\title{
How Many Teeth are Extracted as Part of Orthodontic Treatment? A Survey of 2038 UK Residents
}

Research Article

Mew J ${ }^{1 *}$, Trenouth $\mathrm{M}^{2}$

${ }^{1}$ The London School of Facial Orthotropics, 16-19 Pampisford Road, Croyden, London, CR8 2NE, UK.

${ }^{2}$ Consultant Orthodontist (Retired), Royal Preston Hospital, Sharoe Green Lane, Preston, PR2 9HT, UK.

\section{Abstract}

Background: The extraction rate is defined as the number of patients having permanent teeth extracted as a percentage of the total treatment sample. Reports of extraction rate in the literature vary dramatically from $0.2 \%$ to $80 \%$. Over the last 20 years these appear to have reduced to lower levels owing to the popularity of non-extraction orthodontics.

Objective: Previous estimates of extraction rates have been based on restricted groups which may well introduce bias. To avoid this the present study was undertaken to look at a random sample of the general population.

Method: A questionnaire survey was conducted on a random sample of the UK wide population using an online survey.

Results: Surprisingly high rates were found for extraction of 1 to $6+$ teeth, $50 \%$ for $18-24$ years and 75 to $80 \%$ for all other age groups. There was no difference between males and females $(p=0.217)$ or between different age groups $(p=0.738)$. Third molar extractions were significantly greater in the older age groups $(p=0.000)$ whilst there was no difference for impaction with age $(\mathrm{p}=0.230)$.

Conclusion: The dramatic variation in extraction rates reported over the last 100 years was not reflected in the general population where there was no change with age. Rates were vastly greater than expected from those currently reported in the literature. The significant reduction in third molar removal in the younger age groups could well indicate the influence of NICE guidelines.

Keywords: Extraction Rate; Random Sample; UK Wide Survey; Orthodontic Treatment; Third Molar Removal; NICE Guidelines.

\section{Introduction}

The extraction of teeth has been a common feature of orthodontic treatment since the earliest days of the specialty. However there has been surprising little research performed into the actual numbers of teeth extracted for orthodontic purposes. Extraction frequency is defined as the number of patients having permanent teeth extracted as a percentage of the total treatment sample.

In their classic article on the subject Peck and Peck [1] reported extraction frequencies taken from 12 studies over a 66 year period, that varied between $6.5 \%$ to $83.5 \%$. They also recognised that the decision to extract teeth as part of orthodontic treatment was both contentious and emotive. To quote "For years the question of extracting permanent teeth as part of corrective orthodontics has provoked professional controversy and debate, often of religious intensity".

As early as 1743 Robert Bunon [2] stated that "it is better to have fewer teeth than to have the usual number in a badly arranged fashion". Conversely Pierre Joackim Lefoulon [3] in 1841 expressed the view that "extracting is not healing but destroying". Walter Harris Coffin [4] in 1881 concluded that "extraction of possible sound teeth may of course be necessary though these (cases) are somewhat less numerous than usually imagined and a possible alternative (expansion) in many instances affords satisfactory results".

The question of extraction in orthodontia was the title and subject of a famous and prolonged debate in the pages of the

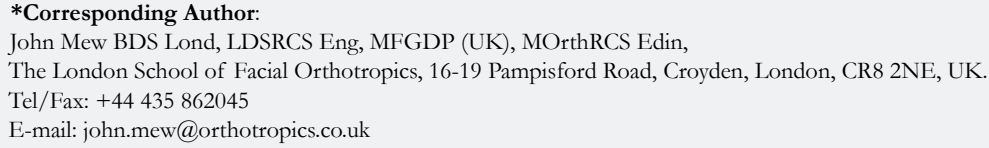

Citation: Mew J, Trenouth M. How Many Teeth are Extracted as Part of Orthodontic Treatment? A Survey of 2038 UK Residents. Int J Dentistry Oral Sci. 2018;S1:02:001:1-5. doi: http://dx.doi.org/10.19070/2377-8075-SI02-01001

Copyright: Mew J ${ }^{\circ}$ 2018. This is an open-access article distributed under the terms of the Creative Commons Attribution License, which permits unrestricted use, distribution and reproduction in any medium, provided the original author and source are credited. 
Dental Cosmos 1912 to 1913 primarily between Calvin Case and Martin Dewey a student of Edward Hartley Angle. Case strongly criticised the non-extraction dogma of Angle as it did not take into account the effect of incisor protrusion on facial aesthetics. Case [5] concluded that "when the whole question of extraction in orthodontia is summed up and the full truth is grasped, it seems a most senseless thing for men to fight over, when the truth is so self-evident; and then to quibble and cast untruthful slurs - among men whose main object in life should be for the development of truth, true principles, and true methods of practice for the advancement of their profession, and the relief of suffering humanity!"

However relapse not aesthetics was the major reason why Tweed [6] and Begg [7] abandoned the non-extraction treatment they had been taught by Angle.

A number of institutional based studies have shown that the extraction rate can vary considerably over time largely attributed to changes in clinical philosophy. Proffit [8] found the extraction rate increased from $30 \%$ in 1953 to a peak of $76 \%$ in 1968 before falling again to $28 \%$ in 1993 . This was largely due to a surge in four first premolar extractions being $10 \%$ in 1953, rising to $50 \%$ in 1968 and dropping slowly back to $10 \%$ in 1993. Janson et al., [9] showed a reduction in the extraction rate from $85.7 \%$ in the period 1973 to 1977 to $45.45 \%$ in 2003 to 2005 again largely as a result of reduction in four first premolar extractions. These declined dramatically from $54.29 \%$ in $1973-1997$ to $7.47 \%$ in 2003 - 2005. Dardengo et al., [10] found a $20 \%$ reduction in 32 years from $61.1 \%$ in 1980 to $40.8 \%$ in 2011 . The extraction rates of four first premolars was not reported in this study. Jackson et al., [11] showed a mild decrease from $37.4 \%$ in 2000 to $22.9 \%$ in 2011. Extraction of four first premolars decreased from 16.5 $\%$ to $8.9 \%$ over the same period. Peck in 2017 [12] showed that reported extraction rates changed dramatically over the past 110 years as follows: Angle 1902 0.2\%, Case 1913 6.5\%, Friel 19318 \%, Proffit $195330 \%$, Proffit $196370 \%$, Tweed $196680 \%$, Peck $197942 \%$, Proffit $199328 \%$, Damon $2000<5 \%$, Greenfield $2010<1.5 \%$.

It is clearly important for orthodontists and the public to be aware of the current average extraction rates in the general population as well as individual institutions. The current research survey was undertaken to collect up to date information pertaining to extraction rates in different age groups and related information on third molar removal and impaction.

\section{Method}

A questionnaire survey was conducted by Populus a professional polling company between $11^{\text {th }}$ and $12^{\text {th }}$ January 2017. All regions of England, Scotland and Wales were included. A survey was conducted online with a nationally representative sample of 2038 adults (18+ years) 993 (49\%) male and 1045 (51\%) female. Respondents were randomly selected from an online panel of 150,000 adults with quotas set on age, gender, region and social grade and the data weighted to the known profile of Great Britain using age, gender, region, social grade, having taken a foreign holiday in the last 3 years, tenure, number of cars per household and working status.
Targets for quotas and weights were taken from the National Readership survey, a random probability face to face survey conducted annually with 34,000 adults. This is used as an update to the census which is now several years out of date. The online surveys have a number of quality control measures to ensure that respondents spent time and care answering questions and did not speed through or contradict themselves at any point in the survey suggesting that they are not concentrating.

The first 2038 adults selected on the basis of demographic criteria all answered Question 1. Have you ever had orthodontic treatment? $594(29 \%)$ had orthodontic treatment whilst 1412 (69\%) had not had and 32 (2\%) did not know. Of the 594 respondents who had orthodontic treatment $252(42.4 \%)$ were male and $342(57.6 \%)$ were female. They were all subsequently asked Questions 2 and 3. There was no recall bias as participants were all questioned at only one point in time. All those surveyed responded to the questions.

The number of participants chosen were enough to ensure they were evenly matched in terms of age, social grade, geographic region and employment sector. This was due to the random selection procedure with between 21 and $38 \%$ in each category who answered yes to question 1 . There were 6 age groups: 18$24,25-34,35-44,45-54,55-64,65+$ years. 4 social grades: A B combined, C1, C2, and D E combined. 11 geographical regions: Scotland, North East, North West, Yorkshire \& Humberside, West Midlands, East Midlands, Wales, Eastern, London, South East, South West. Lastly employment sector either public or private.

Question 2 was: To the best of your recollection, how many teeth did you have extracted as part of your orthodontic treatment?

Question 3 was: Since then, have you had any of your wisdom teeth extracted or have any of your wisdom teeth impacted?

The results of Questions 2 and 3 were presented as all or none discontinuous data using contingency tables. They were then subjected to statistical testing using non-parametric Chi-square analysis. They were also presented graphically in Figures 1 to 3, which clearly demonstrated the findings.

\section{Results}

Question 1: Have you ever had orthodontic treatment?

Of the 2038 respondents 594 (29\%) had orthodontic treatment whilst $1412(69 \%)$ had not and $32(2 \%)$ did not know. Of those who had treatment 252 (42\%) were male and $342(58 \%)$ female. A Chi-square test was non significant (Chi-square $=1.45 \mathrm{p}=$ 0.228 ) indicating no difference between males and females other than chance variation.

There was also no statistically significant difference between the different age groups (Chi-square $=9.69 \mathrm{p}=0.085)$.

Question 2: To the best of your recollection, how many teeth did you have extracted as part of your orthodontic treatment?

Of the 594 respondents who had orthodontic treatment 133 $(22 \%)$ were treated non extraction. Very few had asymmetrical 
Figure 1. Percentage of Teeth Extracted in Males and Females.

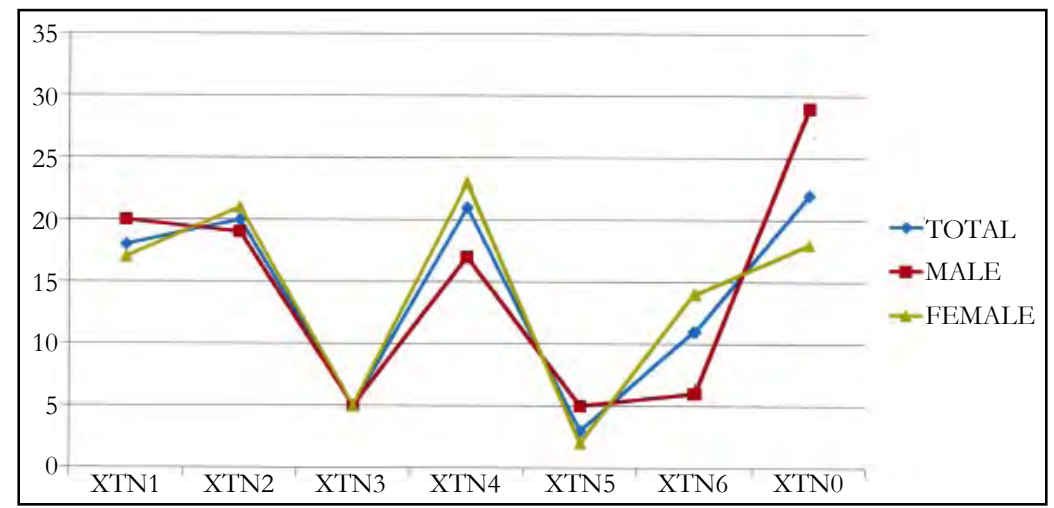

Figure 2. Percentage of Teeth Extracted at Different Ages.

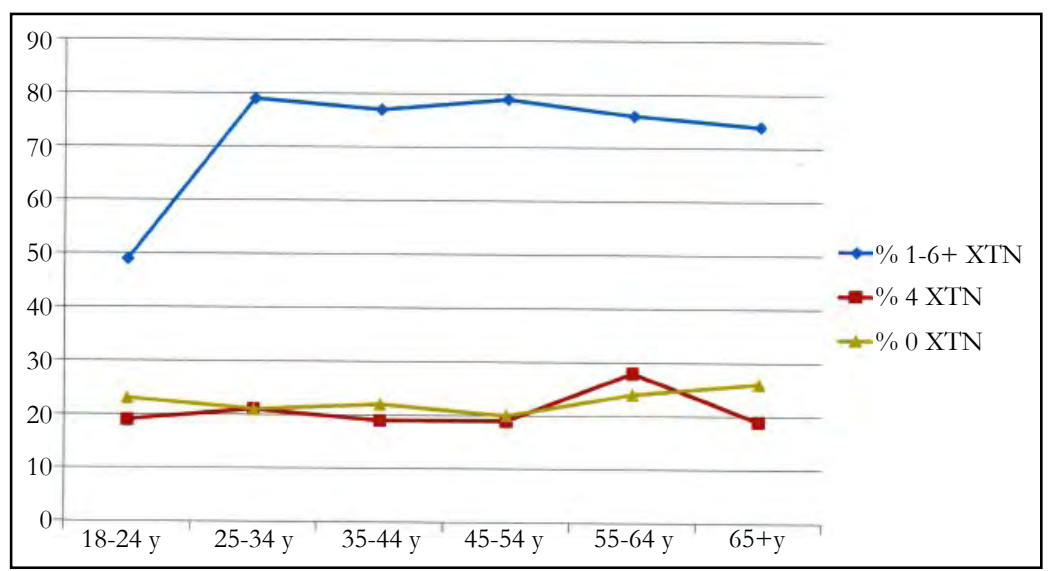

Figure 3. Percentage of Third Molars Extracted and Impacted at Different Ages.

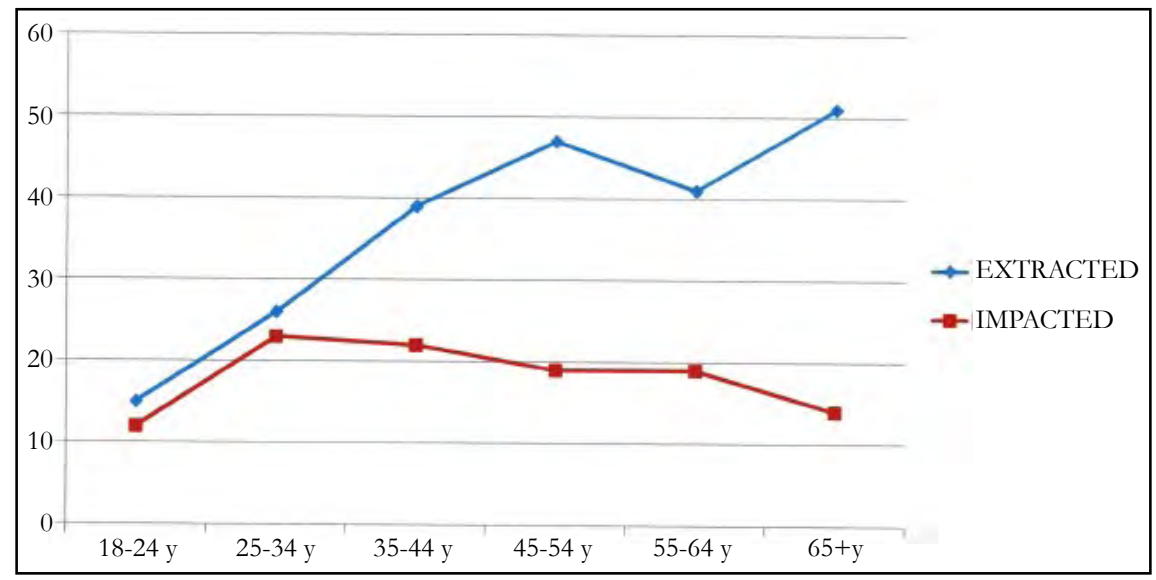

numbers of extractions of 3 teeth $28(5 \%)$ or 5 teeth $20(3 \%)$ teeth. It was not uncommon to have a single tooth extracted 107 (18\%). It was most common to have two $120(20 \%)$ or four 122 $(21 \%)$ teeth extracted. This is most likely to be associated with active appliance therapy of some form. The number having six or more extractions was $65(11 \%)$.

The percentage of teeth extracted for males and females separately is presented in Figure 1 and follows the same trend as for the total number. A Chi-square test was performed to see if there were any differences that were unlikely to arise other than by chance. This was non-significant (chi-square $=8.3, \mathrm{p}=0.217$ ) indicating no difference between males and females.
The percentage of respondents who had 1 to $6+$ teeth or 2 or 4 teeth extracted and those treated non extraction for the different age groups is presented in Figure 2. For the 18 - 24 year age group only $50 \%$ had extractions of 1 to $6+$ teeth compared with 75 to $80 \%$ for the other age groups. The results for those who had 2 or 4 teeth extracted were very similar to those treated without extractions. A Chi-square test did not however demonstrate any statistically significant difference between any of the groups (chisquare $=6.9, \mathrm{p}=0.738)$ indicating no change with age.

Question 3: Since then, have you had any of your wisdom teeth extracted or have any of your wisdom teeth impacted? 


\section{Extracted}

The percentage of third molars extracted was $32 \%$ in males and $40 \%$ in females. A Chi-square test was non significant (Chisquare $=0.14 \mathrm{p}=0.709)$ indicating no difference between males and females.

The percentage of third molars extracted at different ages is presented in Figure 3. A Chi-square test was highly significant (Chi-square $=40.1 \mathrm{p}=0.000$ ) indicating a difference that was unlikely to occur purely by chance. Figure 3 clearly shows a greater rate of third molar extraction in the older age groups.

\section{Impacted}

The percentage of third molars impacted was $17 \%$ in males and $19 \%$ in females. A Chi-square test was non significant (Chi-square $=0.14 \mathrm{p}=0.709)$ indicating no difference between the sexes.

The percentage of third molars impacted at different ages is presented in Figure 3. A Chi-square test was non significant (Chisquare $=6.88 \mathrm{p}=0.230$ ) indicating no change with age.

\section{Discussion}

The dangers of self-reporting are well known and polling numbers can be influenced by prejudice or forgetfulness. However the subjects in this study do not appear to have had any motive to exaggerate or minimize the number of extractions although with the passing of time it is possible that some extractions might have been forgotten. We also have little idea whether the extraction of the wisdom teeth was related to the orthodontic treatment.

The present study was the first open survey to be performed on a UK wide population. The methodology used by the polling company ensured that the respondents were as near as possible to a random sample of the general population. This is in contrast to previous estimates which have been institutional or technique based studies and only representative of specific groups of patients.

The findings of previous studies reflect the fact that non extraction methods have been popular for the last twenty to thirty years. A number of factors have influenced the decline in the extraction rate. 1 . Studies on long - term stability have shown relapse in dental crowding despite extractions [13, 14]. 2. The treatment time for non - extraction cases has been shown to be 3 to 6 months shorter than extraction cases [15]. 3. Concern has been expressed about temporomandibular joint dysfunction related to extraction of premolars [16]. 4. Technique changes have made it easier to manage non - extraction cases such as expansion and functional treatment [16] and low anchorage fixed appliance techniques some of which reduce extraction rates to $5 \%$ and below [12]. 5. There has been greater awareness of the influence of extractions on the soft tissue profile and a general acceptance that a more protrusive profile is aesthetically more desirable [17]. 6. Airway considerations have recently become an important issue in relation to sleep apnoea. Extraction of premolars and incisor retraction reduces the airway dimensions in Class II cases which compared to Class I have a smaller airway to start with. Conversely functional appliance treatment increases the airway dimensions [18].

In the present study the extraction rate of 1 to $6+$ teeth was 75 to $80 \%$ in all age groups except 18 - 24 years which was $50 \%$. Even this was high compared to the rate of 15 to $25 \%$ recommended by Peck in 2017 [12]. The extraction rate for two teeth was $20 \%$ and four teeth $21 \%$ which was most likely to be associated with active appliance treatment still gave an overall rate of $41 \%$ which is again high. More importantly these rates have not changed with age which is clearly shown graphically (Figure 2).

For some reason far more teeth are being extracted than anyone realizes, the British Orthodontic Society Guidelines make little mention of extractions. The present study clearly demonstrates that the changes reported for institutional and technique based studies have not been reflected by similar changes in the general population. This would suggest that the change in concepts that has occurred over the years has not been taken up by the majority of practitioners to the same extent as leading specialists. Also the concept put forward by Tweed that permanent teeth need to be extracted in order to prevent long term re-crowding is still a widely held view [19]. The problem is that there is little or no consensus or evidence base to support the criteria for orthodontic extractions.

For the last decade more clinicians have been trying to avoid extractions during treatment by retracting the upper first molars in order to increase room for the anterior teeth. Obviously this reduces space at the back of the arch which may lead to the extraction of more third molars. Naturally the incidence of third molar extraction is not apparent until sometime after the completion of most orthodontic treatment. For this reason the loss of third molars has often not been included in the past when assessing the rate of extractions. It has been reported that impaction of third molars is greater in non - extraction than extraction patients to a degree that is statistically significant [2022]. This indicates the importance of including third molars in extraction rate studies.

The number of third molars impacted did not change with age (Figure 3). This was consistent with the extraction rates of other teeth which also did not change with age. However the percentage of third molars removed increased significantly with age (Figure $3)$. The reduction in the younger age groups could well indicate the influence of NICE guidelines on third molar removal in recent times.

\section{Conclusions}

1. The present study was the first to use a random sample of the general population to measure extraction rates. All age groups, social grades and geographical areas of the UK were included. Previous estimates have been based on restricted groups which may well introduce bias.

2. Surprisingly high rates were found for extraction of 1 to $6+$ teeth, $50 \%$ for $18-24$ years and 75 to $80 \%$ for all other age groups. Rates were vastly greater than expected from those currently reported in the literature based on restricted groups of patients. Peck in 2017 recommended an extraction rate of between 15 and $25 \%$.

3. Extraction rates did not appear to change with age. This 
is contrary to the fact that extraction rates reported in the literature from restricted groups have varied dramatically from 0.2 to $80 \%$ over the last 100 years or so.

4. The number of third molars impacted did not change with age but the number removed increased significantly with age. The reduction of third molar extraction in the younger age groups could well indicate the influence of NICE guidelines introduced in recent times.

\section{Acknowledgements}

We should like to thank Chris Menzies and Ed Phillips from Populus for technical advise regarding the survey. We should also like to thank the British Dental Association Library for obtaining many of the references.

\section{References}

[1]. Peck S, Peck H. Frequency of tooth extraction in orthodontic treatment. Am J Orthod. 1979 Nov;76(5):491-6. PubMed PMID: 292311.

[2]. Bunon R. Essay on the diseases of the teeth. Briasson; 1743.

[3]. Lefoulon J. New theoretical and practical treatise on the art of the dentist, with a hundred and thirty figures on wood. Fortin, Masson and Co.1841.

[4]. Coffin W H. A generalized treatment of irregularities. J Br Dent Ass. $1881 ; 2: 587-595$.

[5]. Case CS. The question of extraction: an answer to Dr. Ferris' discussion. Dent Cosmos. 1913;55:54-55.

[6]. Tweed CH. A philosophy of orthodontic treatment. Am J Orthod. 1945; 31: 74-85.

[7]. Begg PR. Stone Age man's dentition: with reference to anatomically correct occlusion, the etiology of malocclusion, and a technique for its treatment. Am J Orthod Dentofac Orthop. 1954 Apr 1;40(4):298-312.

[8]. Proffit WR. Forty-year review of extraction frequencies at a university orthodontic clinic. Angle Orthod. 1994;64(6):407-14.PubMedPMID: 7864461.

[9]. Janson G, Maria FR, Bombonatti R. Frequency evaluation of different extraction protocols in orthodontic treatment during 35 years. Progress in orthodontics. 2014 Dec1;15(1):51-58.

[10]. Dardengo CD, Fernandes LQ, Capelli Júnior J. Frequency of orthodontic extraction. Dental Press J Orthod . 2016 Feb;21(1):54-9.

[11]. Jackson TH, Guez C, Lin FC, Proffit WR, Ko CC. Extraction frequencies at a university orthodontic clinic in the 21 st century: demographic and diagnostic factors affecting the likelihood of extraction. Am J Orthod Dentofacial Orthop. 2017 Mar 1;151(3):456-62.

[12]. Peck S. Extractions, retention and stability: the search for orthodontic truth. Eur J Orthod. 2017 Apr 1;39(2):109-15.

[13]. Little RM, Wallen TR, Riedel RA. Stability and relapse of mandibular anterior alignment-first premolar extraction cases treated by traditional edgewise orthodontics. Am J Orthod. 1981 Oct;80(4):349-65. PubMed PMID: 6945805 .

[14]. Little RM, Riedel RA, Engst ED. Serial extraction of first premolars-postretention evaluation of stability and relapse. The Angle Orthodontist. 1990 Dec;60(4):255-62. PubMed PMID: 2256562.

[15]. Vig PS, Orth D, Weintraub JA, Brown C, Kowalski CJ. The duration of orthodontic treatment with and without extractions: a pilot study of five selected practices. American Am J Orthod Dentofac Orthop. 1990 Jan 1;97(1):45-51. PubMed PMID: 2296943.

[16]. Broadbent JM. Crossroads: acceptance or rejection of functional jaw orthopedics. Am J Orthod Dentofac Orthop. 1987 Jul 1;92(1):75-8.

[17]. Ghaleb N, Bouserhal J, Bassil-Nassif N. Aesthetic evaluation of profile incisor inclination. Eur J Orthod. 2011;33:228-235. PubMed PMID: 20716642.

[18]. Trenouth M J, Desmond S R. A cephalometric evaluation of oropharyngeal airway changes during Twin-block appliance treatment. Int J Dentistry Oral Sci. 2016;S4:004:22-30.

[19]. Powell S. Short-term orthodontics: History puts it straight. Br Dent J. 2014 Jul; 217(1):4.

[20]. Kim TW, Årtun J, Behbehani F, Artese F. Prevalence of third molar impaction in orthodontic patients treated nonextraction and with extraction of 4 premolars. Am J Orthod Dentofac Orthop. 2003 Feb 1; 123(2):138-45. PubMed PMID: 12594419.

[21]. Salehi P, MomeneDanaie S. Lower third molar eruption following orthodontic treatment. Eastern Mediterr Health J. 2008;14:1452-1458. PubMed PMID: 19161121.

[22]. Patel AK, Deshmukh SV, Naik CR, Jethe S, Patel KA. Radiographic assessment for predicting the mandibular third molar eruption after orthodontic treatment in first premolar extraction group and non-extraction group: aretrospective study. Concern. 2015;1:1-6. 